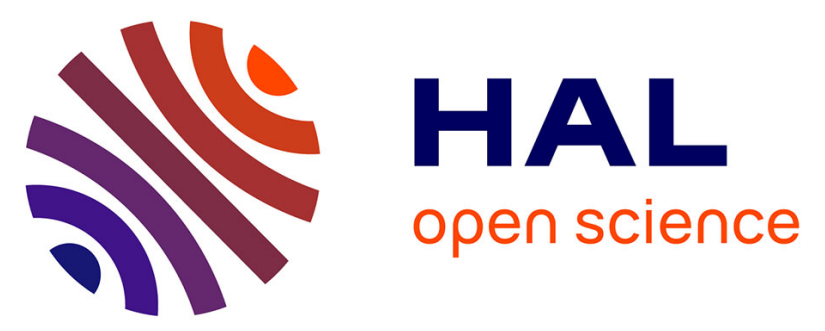

\title{
A chemical library to screen protein and protein-ligand crystallization using a versatile microfluidic platform
}

\author{
Charline J. J. Gerard, Gilles Ferry, Laurent M Vuillard, Jean A. Boutin,
} Nathalie A Ferte, Romain A Grossier, Nadine A Candoni, Stéphane A Veesler

\section{- To cite this version:}

Charline J. J. Gerard, Gilles Ferry, Laurent M Vuillard, Jean A. Boutin, Nathalie A Ferte, et al.. A chemical library to screen protein and protein-ligand crystallization using a versatile microfluidic platform. Crystal Growth \& Design, 2018, 18, pp.5130-5137. 10.1021/acs.cgd.8b00572 . hal-01768463

\section{HAL Id: hal-01768463 \\ https://hal.science/hal-01768463}

Submitted on 17 Apr 2018

HAL is a multi-disciplinary open access archive for the deposit and dissemination of scientific research documents, whether they are published or not. The documents may come from teaching and research institutions in France or abroad, or from public or private research centers.
L'archive ouverte pluridisciplinaire HAL, est destinée au dépôt et à la diffusion de documents scientifiques de niveau recherche, publiés ou non, émanant des établissements d'enseignement et de recherche français ou étrangers, des laboratoires publics ou privés. 


\title{
A chemical library to screen protein and protein-ligand crystallization using a versatile microfluidic platform
}

\author{
Charline J.J. Gerard ${ }^{a}$, Gilles Ferry ${ }^{b}$, Laurent M. Vuillard ${ }^{b}$, Jean A. Boutin ${ }^{b}$, Nathalie \\ Ferte $^{a}$, Romain Grossier ${ }^{a}$, Nadine Candoni ${ }^{a}$, Stéphane Veesler ${ }^{a}$ \\ ${ }^{a}$ CINaM-CNRS, Aix-Marseille Université, Campus de Luminy, Case 913, 13288 Marseille CEDEX 09, France, \\ ${ }^{b}$ Institut de Recherches Servier, 125 Chemin de Ronde, 78290 Croissy-sur-Seine, France.
}

\begin{abstract}
Here, we describe a plug-and-play microfluidic platform, suitable for protein crystallization. The droplet factory is designed to generate hundreds of droplets as small as a few nanoliters ( 2 to $10 \mathrm{~nL})$ for screening and optimization of crystallization conditions. Commercially-available microfluidic junctions and tubing are combined to create the appropriate geometry. In addition, a "chemical library" is produced in tubing. The microfluidic geometry for a "crystallization agent-based chemical library" is validated by screening crystallization conditions of lysozyme. The microfluidic geometry for a "ligand-based chemical library" is also explored to co-crystallize the protein QR2 with a ligand, for the purposes of structure-based drug design. This platform mixes aqueous phases (containing the protein and the crystallization agent) and organic phases (containing the ligand), during the droplet generation and circulation without using any surfactant. The droplet composition is controlled by the respective flow-rates of the different solutions, and checked by measuring online absorbance. The low volumes involved in the crystallization trials, the speed of execution and the absence of a microfabrication stage make our platform a cheap, easy-to-use and versatile tool for crystallization studies.
\end{abstract}

\section{Introduction}

Crystallization is used in many fields (biology, pharmacy, mineralogy, optics, for molecule separation and purification processes, and for control of product properties like size, shape and phase. Crystallization is also used for analytical purposes. For instance, protein crystallization is a key step in the determination of the three-dimensional structure of proteins by X-ray diffraction (XRD), allowing a better understanding of their biological functions. In addition, in pharmaceutical research, the co-crystallization of a target protein with many different ligands often enables the identification and design of new active pharmaceutical ingredients (APIs). This process is called structure-based drug design. ${ }^{1}$ However, obtaining large enough high-quality protein single crystals (about $100 \mu \mathrm{m}$ ) remains a challenge in the determination of protein structures by XRD. ${ }^{2}$

Crystallization is influenced by many parameters $(\mathrm{pH}$, temperature, type of buffer and crystallization agent). Identifying the conditions to obtain suitable protein crystals is usually a twostep process, based on a trial and error approach: first screening and then optimization of crystallization conditions. Moreover, nucleation being of a stochastic nature, it takes a large number of experiments to obtain reliable data. ${ }^{3,4}$ However, proteins are generally expensive to produce and only available in small quantities. Consequently, it is expensive to identify protein crystallization conditions, both in terms of time and raw materials. The volumes involved in crystallization trials are therefore key to reducing experimental costs.

A high-throughput approach to crystallization, and particularly to screening, is thus needed for industrial research and drug design. Two categories of tools have been developed for highthroughput protein-crystallization trials. The first is high-throughput robots, like Mosquito ${ }^{\circledR}$ (TTP LabTech), Oryx8 (Douglas Instruments Ltd), or Phoenix (Art Robbins Instruments). They rely on automated liquid-handling integrated with dispensers and fluidic circuits, and are typically able to form droplets as small as $100 \mathrm{~nL} .^{5}$ However, they are generally expensive. 
The second category of tool is based on microfluidic techniques, i.e. controlling and manipulating flows at low scales (micro, nano to picoliter) with miniaturized devices called lab-onchip. ${ }^{6}$ A very large number of microfluidic systems dedicated to the screening of crystallization conditions is available, based on different crystallization methods ${ }^{7}$ : free interface diffusion ${ }^{8,9}$, counter diffusion ${ }^{10,11}$, vapor diffusion ${ }^{12,13}$, batch ${ }^{14,15}$. Many crystallization experiments are carried out quickly, testing a lot of different crystallization agents at different concentrations. However, most of them are for single use and require complex external equipment (integrated valves and pumps, mixers, especially designed and microfabricated channels or chambers, multiple inlets of pressurized gas). Moreover, these devices may be expensive and/or difficult to use by non-specialists in microfluidics.

We previously described a versatile, high-throughput droplet-based microfluidic platform for optimization of crystallization conditions. ${ }^{16}$ Hundreds to thousands of droplets as small as $2 \mathrm{~nL}$ (hereafter nanodroplets) are generated in an oil flow, using only small quantities of materials. The use of surfactant is avoided because it is liable to disturb the nucleation process. Droplets are isolated from each other by oil, so that each droplet serve as an independent nano-crystallizer. This flexible platform combines material saving, speed of execution, ease of use and a large number of experiments for statistical validity. The parts of the set-up achieving droplet generation, mixing, detection and storage are all independent, commercially available modules and can be assembled according to the user's needs (Figure 1):

(1) The droplet factory: droplets are generated in Teflon tubing, using a syringe pump (Figure 1a) and microfluidic junctions (Figure 1b) in which the dispersed phases (crystallization solutions) intersect an immiscible continuous phase. The dispersed phases mix as they form droplets, and the droplet composition is controlled by the solution flow-rates.

(2) The on-line characterization module: each droplet can be characterized by its size, its frequency and its composition, by spectrophotometry (Figure 1c);

(3) The droplet incubation module: this module involves a thermostatted tubing holder (Figure 1d) and an xyz-motorized camera for sequential acquisition (Figure 1e).

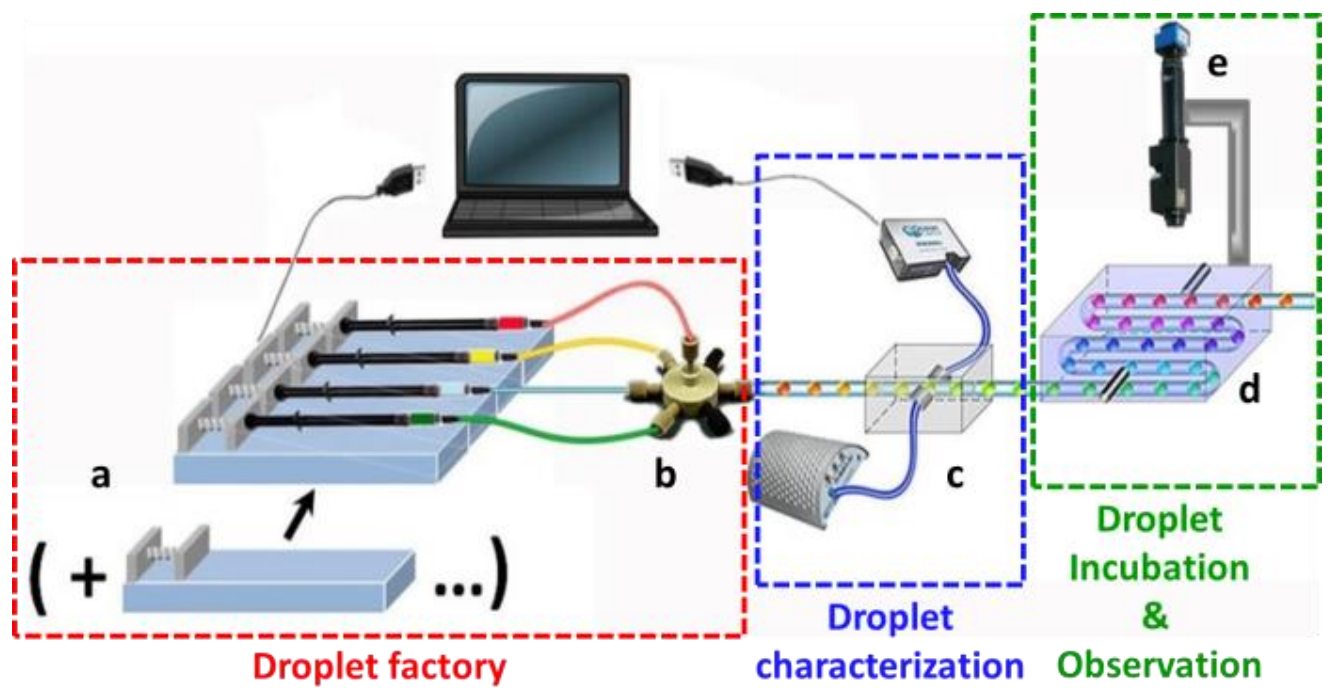

Figure 1: Schematic illustration of the entire microfluidic platform ${ }^{16}$. (a) Syringe pump, (b) microfluidic junction, (c) on-line spectrophotometer, (d) thermostatted tubing holder, (e) xyz-motorized camera.

Here, we describe the serial assembly of microfluidic junctions in the droplet factory without microfabrication. The aim is to increase the number of solution inlets and to adapt the geometry to protein crystallization. To perform screening, tubing is filled with solutions of different components, separated from each other by oil to prevent mixing. This tubing is a "chemical library", containing different components involved in protein crystallization. These solutions are then added to nanodroplets of protein solution. Furthermore, we are able to mix two different phases (aqueous and organic) inside the droplets. Here, our microfluidic platform is applied to screening and 
optimization of crystallization conditions of lysozyme, and to quinone reductase 2 co-crystallization with ligand, for structure-based drug design purposes.

\subsection{Solutions}

All solutions were prepared using deionized pure water (Milli-Q ${ }^{\circledR}$ Direct, Merck Millipore).

\subsubsection{Lysozyme}

Hen-egg white lysozyme (14.6kDa) was purchased from Sigma (batch $057 \mathrm{~K} 7013$ L 2879) and used without further purification. A suitable amount of lysozyme was solubilized in $80 \mathrm{mM}$ sodium acetate buffer at $\mathrm{pH} 4.5$ (pH-meter $\mathrm{pH} 210$, HANNA Instruments). The lysozyme concentration of the solution was checked by measuring absorbance (Nanodrop ${ }^{\circledR}$ ND2000c) at 280nm $\left(\varepsilon_{\text {lysozyme }}=2.64 \mathrm{~mL} \cdot \mathrm{cm}^{-1} \cdot \mathrm{mg}^{-1}\right){ }^{17}$. The $\mathrm{NaCl}(4 \mathrm{M}),\left(\mathrm{NH}_{4}\right)_{2} \mathrm{SO}_{4}(4 \mathrm{M})$ and $\mathrm{KSCN}(0.6 \mathrm{M})$ solutions were prepared in acetate buffer.

\subsubsection{QR2}

Human quinone reductase 2 (QR2, also known as NQO2; EC 1.10.5.1) was produced in Escherichia coli (Protenia). Before use, flavin adenine dinucleotide (FAD) was added at a ratio of $1.5 \mathrm{~mol}$ of FAD for $1 \mathrm{~mol}$ of QR2. The protein was then rinsed with its elution buffer (20mM Tris pH 8, $150 \mathrm{mM} \mathrm{NaCl}$ ) and concentrated to $35 \mathrm{mg} \mathrm{ml}^{-1}$. QR2 concentration was checked by measuring absorbance at $450 \mathrm{~nm}$ and $280 \mathrm{~nm} \quad\left(\varepsilon_{\mathrm{FAD}}{ }^{450}=11300 \mathrm{~L} \cdot \mathrm{mol}{ }^{-1} \cdot \mathrm{cm}^{-1}, \quad \varepsilon_{\mathrm{FAD}}{ }^{280}=19900 \mathrm{~L} \cdot \mathrm{mol}{ }^{-1} \cdot \mathrm{cm}^{-1}\right.$, $\left.\varepsilon_{\mathrm{QR} 2}{ }^{280}=44920 \mathrm{~L} \cdot \mathrm{mol}^{-1} \cdot \mathrm{cm}^{-1}\right)\left(\right.$ ExPASy, ProtParam $\left.{ }^{18}\right)$. The $\left(\mathrm{NH}_{4}\right)_{2} \mathrm{SO}_{4}(3 \mathrm{M})$ solution was prepared in the same elution buffer. QR2 crystallization conditions in our microfluidic set-up have previously been

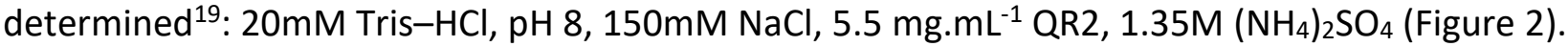

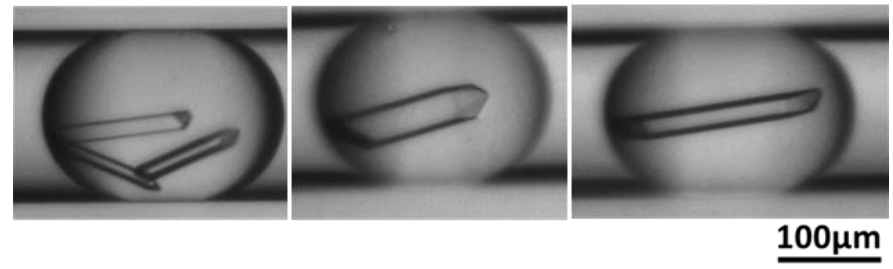

Figure 2: Pictures of 3 representative droplets for QR2 crystallization in $3 \mathrm{~nL}$ droplets. $20 \mathrm{mM}$ Tris- $\mathrm{HCl}$, $\mathrm{pH} 8,150 \mathrm{mM} \mathrm{NaCl}, 5.5 \mathrm{mg}^{\mathrm{mL}} \mathrm{m}^{-1} \mathrm{QR2}, 1.35 \mathrm{M}\left(\mathrm{NH}_{4}\right)_{2} \mathrm{SO}_{4}, 20^{\circ} \mathrm{C}$.

For QR2 co-crystallization experiments, we used a known ligand of this protein, melatonin ${ }^{20}$, solubilized in DMSO (Dimethyl sulfoxide) to $100 \mathrm{mM}$. Then the ligand concentration in solution was adjusted to $6 \mathrm{mM}$ with $63 \%$ water. A surplus of ligand was added to the droplets, at a ratio of 10:1 (n ligand/nQR2).

\subsubsection{Dyes}

Colored solutions were prepared using food dyes in deionized water ( $5 \%$, red dye Vahiné E122 and yellow dye Vahiné E102).

\subsection{Interfacial energy measurement}

Interfacial energies were measured by the hanging drop method ${ }^{21}$, using a contact angle measurement system OCA20 (Dataphysics) with the software SCA20.

\subsection{Microfluidic platform}

\subsubsection{Materials}

The droplet factory was constructed from commercially-available polyetherether ketone (PEEK) junctions and Teflon-like tubing (IDEX Health and Science), initially designed for highperformance liquid chromatography (HPLC) systems. These two materials were previously tested in 
our group and proved to be compatible with almost all solvents, showing excellent resistance and no solvent evaporation ${ }^{22}$.

Droplet generation depends on flow-rates, viscosities, wettability of the tubing wall, interfacial energy between continuous and dispersed phases, tubing dimensions, and crossing angles of microfluidic tubing. ${ }^{23}$ Here, we used fluorinated ethylene propylene (FEP) tubing with inner diameter (ID) of $150 \mu \mathrm{m}$ and outer diameter (OD) of $1.59 \mathrm{~mm}$. Junctions all include an inlet for the continuous phase and an outlet for droplets, plus one or two other inlets to inject the dispersed phase(s), leading to two junction geometries. In a tee-junction (two inlets and one outlet), the dispersed phase and the continuous phase were injected via two perpendicular inlets. In a crossjunction, the continuous phase was injected via the inlet facing the outlet and two dispersed phases were injected face-to-face via the two other inlets. Hence the dispersed phases mix as they form droplets. Both tee- and cross-junctions are $150 \mu \mathrm{m}$ ID so as to generate from 2 to $10 \mathrm{~nL}$ droplets. The flow-rates of the syringes containing the continuous and dispersed phases were precisely controlled (as low as $0.01 \mu \mathrm{L} / \mathrm{s}$ ) without pulses by a programmable pump system (neMESYS, cetoni $\mathrm{GmbH}$ ).

Continuous phase selection is essential for droplet stability. Two parameters are therefore decisive: viscosity, related to molecular weight (at constant chemical composition), and interfacial energy between the continuous phase and the dispersed phase, related to chemical composition. The less miscible the continuous phase is with the dispersed phase, i.e., the higher the interfacial energy, the more stable the droplets. Thus, fluorinated oils are typically chosen. We showed in a previous work how to choose conditions of droplet generation to obtain droplets that are homogeneous, in terms of size and frequency. ${ }^{24}$ Here, we used FC-70 oil (Hampton Research, 3M ${ }^{\text {tM }}$ Fluorinert ${ }^{\mathrm{TM}}$ ) as continuous phase. This oil has no or very poor miscibility with both aqueous and organic solutions and good wettability with Teflon. ${ }^{22}$

The characterization module consisted of a light source (from 215 to $2500 \mathrm{~nm}$, DT-MINI-2-GS, Ocean optics), a home-made tubing-holder (poly(methyl methacrylate)), two optical fibers (diameter $400 \mu \mathrm{m}$, premium-grade Patch Cords, QP400-1-UV-Vis, Ocean optics), a UV-Vis-NIR spectrophotometer (from 190 to $2300 \mathrm{~nm}$, USB2000+, Ocean optics) and software (OceanView, Ocean optics).

The incubation and observation module comprised a thermostatted tubing holder (Anacrismat) and a camera (Alliance Vision) mounted on an xyz-motorized table with a motorized variable zoom.

\subsubsection{Set-up}

The cross-junction enables the mixing of two solutions in the droplets, for instance the protein solution and the crystallization agent solution. However, it may be necessary to add a ligand (for co-crystallization), or another crystallization agent (for screening), or an additive to the crystallization solution. Thus, several microfluidic junctions were mounted together to increase the number of inlets in the set-up. Here, the cross-junction was combined with a tee-junction, allowing a third solution to be injected into the droplets after their generation (Figure 3a). As the solutions injected into the cross and the tee junctions are miscible, the third solution can be added inside the pre-existing droplets. ${ }^{25}$

Mixing was verified visually in a prior trial using yellow and red dyes in $500 \mu \mathrm{m}$ ID tubing (PFATeflon, IDEX health and science), generating larger droplets $(\sim 100 \mathrm{~nL})$. The yellow dye was injected into the cross-junction, while the red dye was injected into the tee-junction (Figure $3 b$ ). Droplet size, and thus homogeneity, was evaluated by length $L$ (from pictures using the software ImageJ), and used to calculate the droplet volume.

Depending on flow-rate, the red solution mixes well with the yellow droplets passing through the tee-junction, without creating a new interface and thus a new droplet. Moreover, at constant flows, the droplets at the outlet of the tee-junction are homogeneous both in terms of size and frequency. For a given size of yellow droplets generated in the cross-junction (i.e., for given flowrates in the cross-junction) (Figure 4a), increasing the flow-rate of the red solution resulted in an 
increased volume of red solution being added to the droplets (Figure $4 \mathrm{~b}$ to $\mathrm{k}$ ). Thus, the amount of solution added to the droplets was controlled by the flow-rate for the third solution, enabling the control of droplet composition.

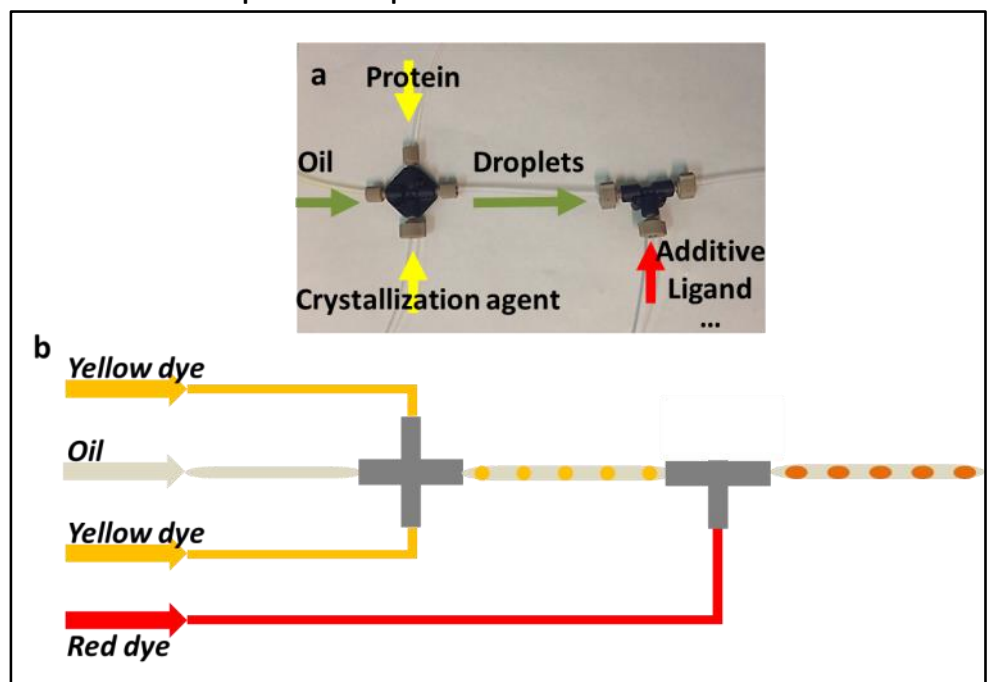

Figure 3: (a) Picture of droplet generation in a cross-junction combined with a tee-junction and (b) schematic representation of a trial with yellow and red dyes.

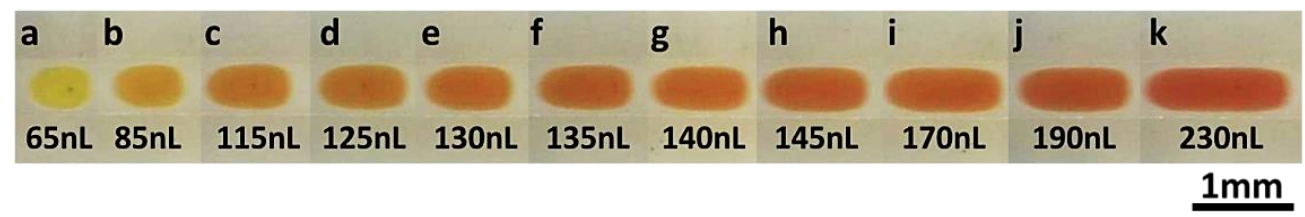

Figure 4: (a) Droplets generated in the cross-junction. (b) to (k) Droplets obtained after adding red solution to yellow droplets through the tee-junction: from (b) to $(k)$, the amount of red dye is increasing. Roughly 100 droplets are generated for each condition to check their that they are homogeneous in size and frequency.

To test the feasibility of this procedure with lower volumes, the same experiment was realized in $150 \mu \mathrm{m}$ ID tubing (i.e. with $\sim 3 \mathrm{~nL}$ droplets). As the droplets were roughly 30 times smaller, the amount of dyed solution added to droplets could not easily be checked visually. Therefore, we placed the on-line spectrophotometer (Figure 1c) after the tee-junction and we determined the red-dye concentration in the droplets by measuring the absorbance at $520 \mathrm{~nm}$. Figure 5 shows that the absorbance is proportional to the red-dye flow-rate, up to $30 \mu \mathrm{L} / \mathrm{h}$. above this threshold, the red-dye concentration falls beyond the linearity domain of Beer-Lambert's law. In that case, we used image analysis to evaluate the concentration via the size of the droplets, which increases with the red-dye flow-rate: for a red-dye flow-rate of $0 \mu \mathrm{L} / \mathrm{h}$, droplet volume is $5 \mathrm{~nL}$, while for a red-dye flow-rate of $80 \mu \mathrm{L} / \mathrm{h}$, droplet volume is $16 \mathrm{~nL}$. Hence the proportion of red dye in droplets increases from 0 to almost $70 \%$, as shown by droplet color under equivalent conditions in $500 \mu \mathrm{m}$ tubing (Figure $4 \mathrm{j}$ ).

These experiments show that several microfluidic junctions can be combined to increase the number of inlets in the set-up. With appropriate flow-rates, the different solutions merge instead of creating new droplets in the tubing, and the amount of solution added to the tee-junction is proportional to the flow-rate. Droplet concentration can then be checked by on-line spectrophotometry. This set-up is applied to both protein-ligand co-crystallization and screening of crystallization conditions. 


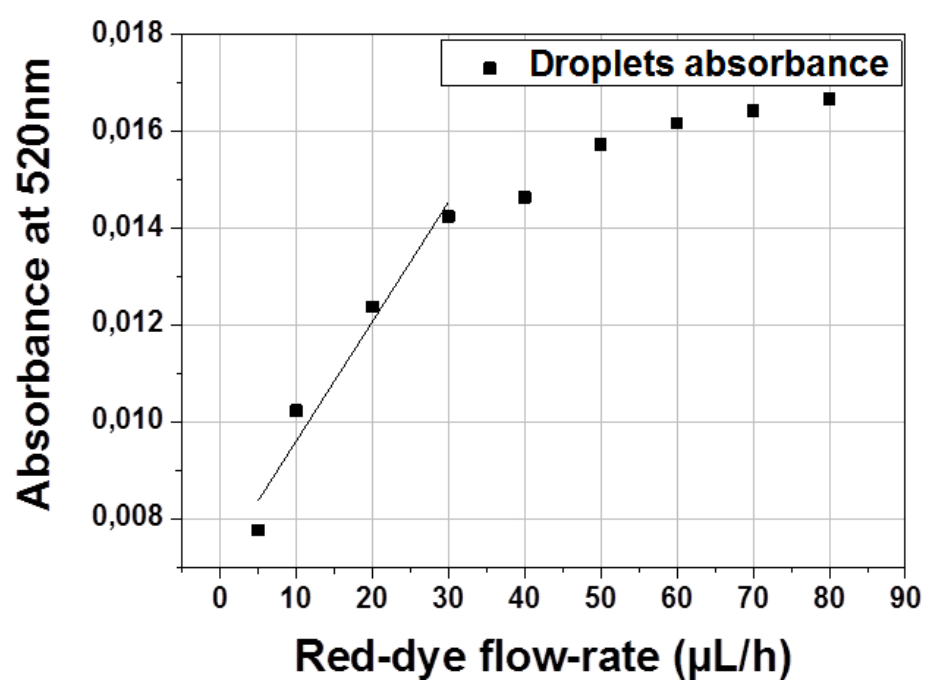

Figure 5: Droplet absorbance at 520nm as a function of the red-dye flow-rate in $150 \mu m$ ID tubing.

\subsubsection{Chemical library}

The syringes used to inject the various fluids into the microfluidic system have a minimum filling volume of roughly $100 \mu \mathrm{L}$. Since microfluidics consumes little material, droplets generation does not consume the entire volume in the syringe, which is wasteful. Our solution is not to fill the syringes, but to fill the tubing directly. To do so, the syringe and tubing of the selected length were first filled with oil (so as not to contaminate the solutions) and then the tubing was refilled with the solution of interest. This system was applied to screening by successively refilling the same tubing with plugs of different solutions (Figure 6). This tubing is the "chemical library" for the screening experiment. The solutions were separated from each other by an oil spacer to prevent them from mixing. Then the solutions were injected successively into the microfluidic system. ${ }^{14}$ For instance, a length of $15 \mathrm{~cm}$ of $150 \mu \mathrm{m}$ ID tubing contains $\sim 2.7 \mu \mathrm{L}$, corresponding to about 900 droplets of $3 \mathrm{~nL}$. Consequently, using plugs instead of syringes considerably reduces the consumption of materials, for instance by a factor 37 for 900 droplets. The length of the plugs, and thus their volume, depends on the number of droplets required by the user.

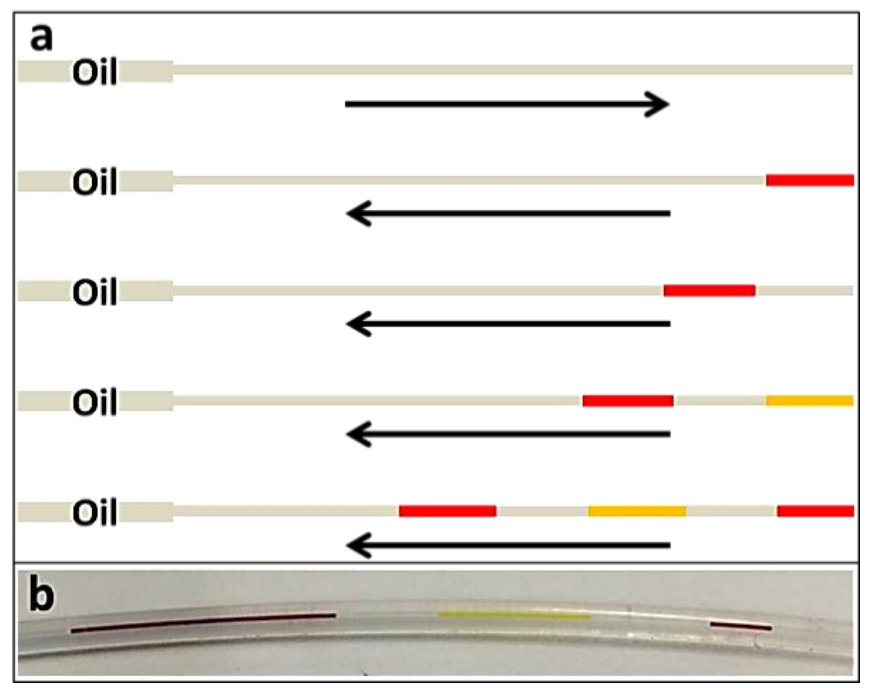

Figure 6: Filling tubing with different solutions. (a) The tubing is first filled with oil (grey), and then refilled with the first solution (red). The tubing can be filled with different solutions, by interspacing oil between solutions. (b) Picture of tubing (FEP, $1.59 \mathrm{~mm} O D, 150 \mu \mathrm{m} I D)$ containing first a red $(0.22 \mu \mathrm{L})$, then a yellow $(0.13 \mu \mathrm{L})$ and then a red dye $(0.05 \mu \mathrm{L})$, separated from each other by $\mathrm{FC}-70$ oil. Arrows indicate the flow direction. 


\section{Screening of crystallization conditions of lysozyme}

To apply our microfluidic platform to the screening of protein crystallization conditions, different solutions of crystallization agents have to be added successively to droplets. We performed a first experiment in $150 \mu \mathrm{m}$ ID tubing, using dyes instead of crystallization agents to make it easier to observe the droplets. Tubing containing dyes served as the "crystallization agent-based chemical library tubing": we inserted a red plug, a yellow plug and another red plug (top of Figure 6), separated from each other by oil. Droplets were generated in a cross-junction, by injecting two flows of water face-to-face (instead of crystallization solution) and perpendicularly separated by FC-70 oil. The tubing at the cross-junction output was connected to a tee-junction. The dyes were added to droplets by connecting the tubing containing dyes to the tee-junction (Figure 7). At the tee-junction output, the droplets obtained were successively transparent (Figure 7a), red (Figure 7b), transparent (Figure 7c), yellow (Figure 7d), transparent (Figure 7e) and red (Figure 7f). Thus, the different dyes and the oil contained in the tubing were injected successively into the droplets generated in the crossjunction. There was no mixing between the different plugs. Droplets not containing dye, i.e. those that had passed through the tee-junction during oil injection, were very irregular in terms of size and frequency. The oil injection obviously destabilized the droplets, inducing their coalescence. conversely, the droplets to which dyes had been added were homogeneous ( $L \sim 400 \mu \mathrm{m}$, i.e. $6 \mathrm{~nL}$ ). Thus, using "chemical library tubing" and a tee-junction, it is possible to add different aqueous solutions successively to aqueous droplets after their generation in a cross-junction.

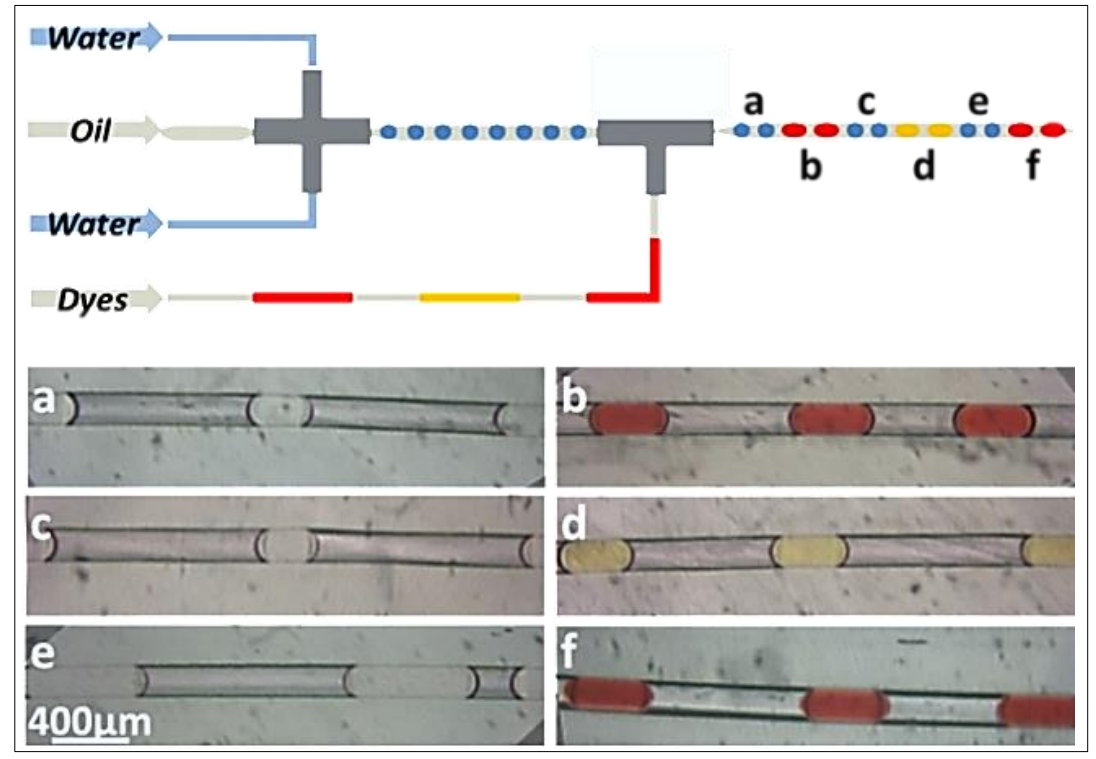

Figure 7: Successive addition of different solutions inside the droplets using the tee-junction and $150 \mu \mathrm{m}$ ID tubing. (a) to (f) show droplets obtained from the addition of: (b-d-f) dyes and (a-c-e) oil. The flow-rates are: oil $130 \mu \mathrm{L} / \mathrm{h}$, water $60 \mu \mathrm{L} / \mathrm{h}$ and dyes $20 \mu \mathrm{L} / \mathrm{h}$.

The same set-up was used to add different crystallization agents to lysozyme droplets, to screen lysozyme crystallization conditions. Three crystallization agents were tested: $\left(\mathrm{NH}_{4}\right)_{2} \mathrm{SO}_{4}, \mathrm{NaCl}$ and $\mathrm{KSCN}$ (top of Figure 8). Adding $\left(\mathrm{NH}_{4}\right)_{2} \mathrm{SO}_{4}$ yielded no crystallization event (Figure 8a). Adding $\mathrm{KSCN}$ led to precipitates of lysozyme in the droplets (Figure $8 \mathrm{~b}$ ). Adding $\mathrm{NaCl}$ led to lysozyme crystals with two crystal habits (Figure $8 \mathrm{c}$ ) that were previously observed ${ }^{26,27}$ : the first is the tetragonal stable phase and the second, with a sea-urchin-like habit, is a metastable phase. ${ }^{26}$ Here, applying our screening strategy to lysozyme led us to select $\mathrm{NaCl}$ as a crystallization agent. Thus, our microfluidic platform can be used to screen crystallization conditions of proteins by successively injecting different crystallization agents into protein droplets. 


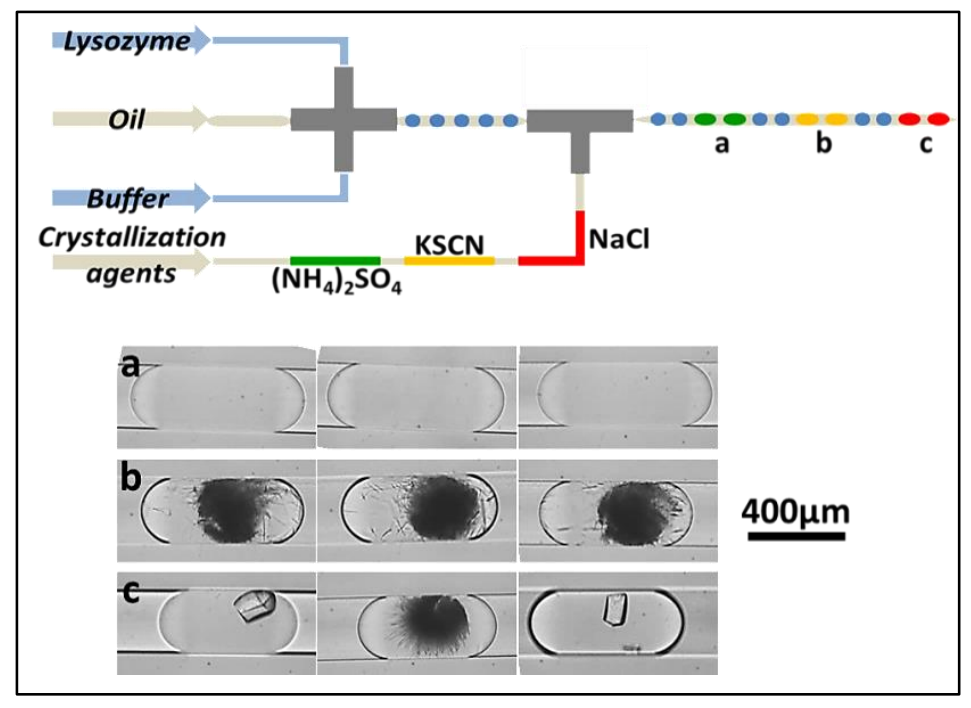

Figure 8: Screening of crystallization conditions of lysozyme. Three crystallization agents are injected into $10 \mathrm{~nL}$ droplets. Crystallization conditions are lysozyme $33 \mathrm{mg} / \mathrm{mL}$ in a buffer of sodium acetate $80 \mathrm{mM} \mathrm{pH} 4.5,20^{\circ} \mathrm{C}$ (a) $\left(\mathrm{NH}_{4}\right)_{2} \mathrm{SO}_{4} 1.1 \mathrm{M}$, (b) $\mathrm{KSCN} 170 \mathrm{mM}$, (c) $\mathrm{NaCl} 1.2 \mathrm{M}$. Flow-rates are: oil 130 $\mathrm{LL} / \mathrm{h}$, lysozyme $25 \mu \mathrm{L} / \mathrm{h}$, buffer $25 \mu \mathrm{L} / \mathrm{h}$, crystallization agents $20 \mu \mathrm{L} / \mathrm{h}$. These three sets of droplets are obtained in a single experiment. About 50 droplets are generated for each condition to check their regularity.

Then, the crystallization conditions were optimized using the fine-gradient method $^{16}: \mathrm{NaCl}$ and lysozyme solutions were injected into a cross-junction, varying the respective flow-rates to create a concentration gradient inside the droplets (top of Figure 9). In this way, a wide range of supersaturation was scanned. We obtained large single crystals of protein (Figure 9b). Thus, our microfluidic platform permits the screening and the optimization of crystallization conditions of proteins in droplets as small as $3.5 \mathrm{~nL}$, consuming little material $(\sim 0.2 \mathrm{mg}$ of protein in total) and without using any surfactant. Moreover, the large number of identical droplets (at least 50 per condition) avoids the risk of false negative or positive results, and the final selection of crystallization condition is robust and reproducible.

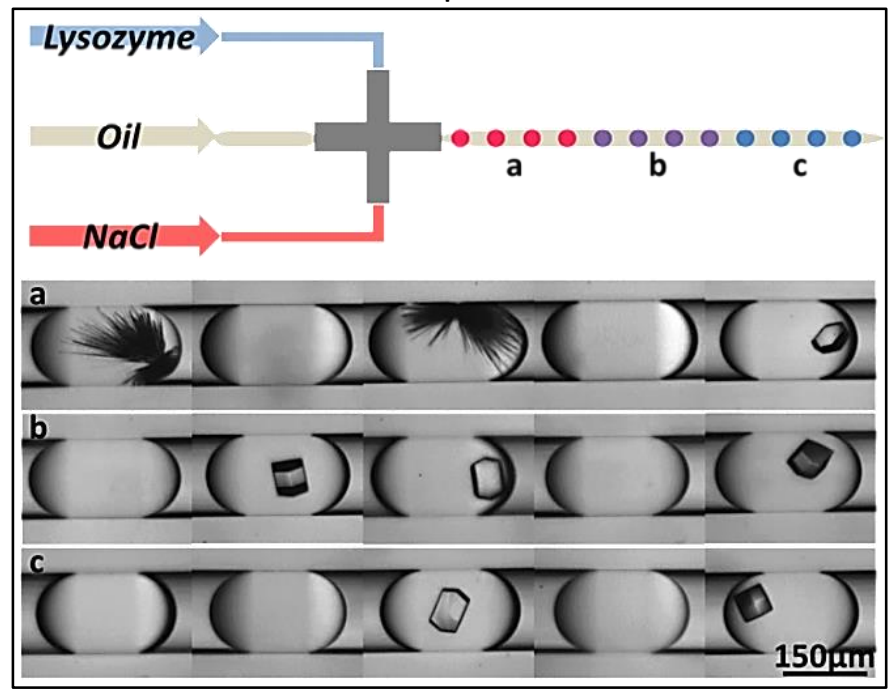

Figure 9: Optimization of crystallization conditions of lysozyme with the concentration gradient

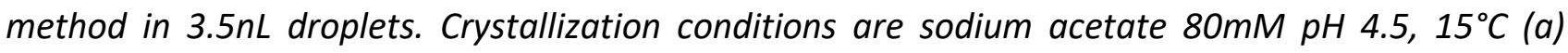
Lysozyme $23 \mathrm{mg} / \mathrm{mL}$, $1.33 \mathrm{M} \mathrm{NaCl}$, (b) Lysozyme $35 \mathrm{mg} / \mathrm{mL}$, $1 \mathrm{M} \mathrm{NaCl}$, (c) Lysozyme $47 \mathrm{mg} / \mathrm{mL}, 0.66 \mathrm{M}$ $\mathrm{NaCl}$. These three sets of droplets are obtained in a single experiment. About 50 droplets are generated for each condition to check their regularity. 


\section{Screening of ligands of QR2 by co-crystallization}

Our microfluidic platform can also be applied to the screening of ligands of proteins for structure-based drug design. To perform protein-ligand co-crystallization, the protein and the ligand have to be incubated together before surpersaturation is generated. Thus, protein and ligands were first mixed in the cross-junction, and second, the crystallization agent was introduced into the teejunction. The length of the tubing between the cross- and the tee-junctions was adapted to the ligand-protein binding affinity (the lower the binding affinity, the longer the tubing).

A first experiment was performed in $150 \mu \mathrm{m}$ ID tubing, using dyes instead of ligands to make it easier to observe the droplets. Tubing containing dyes (the "ligand-based chemical library tubing"), and water (mimicking the protein solution) were used, as in part 2. Water and dyes were injected face-to-face into a cross-junction, generating dyed droplets in oil. Then water (mimicking the crystallization agent solution) was injected into droplets via a tee-junction (top of Figure 10). Mixing water with dyed droplets in the tee-junction led to colored droplets that were homogeneous both in terms of size and frequency (Figure 10b, $d$ and f), as in the part 2.

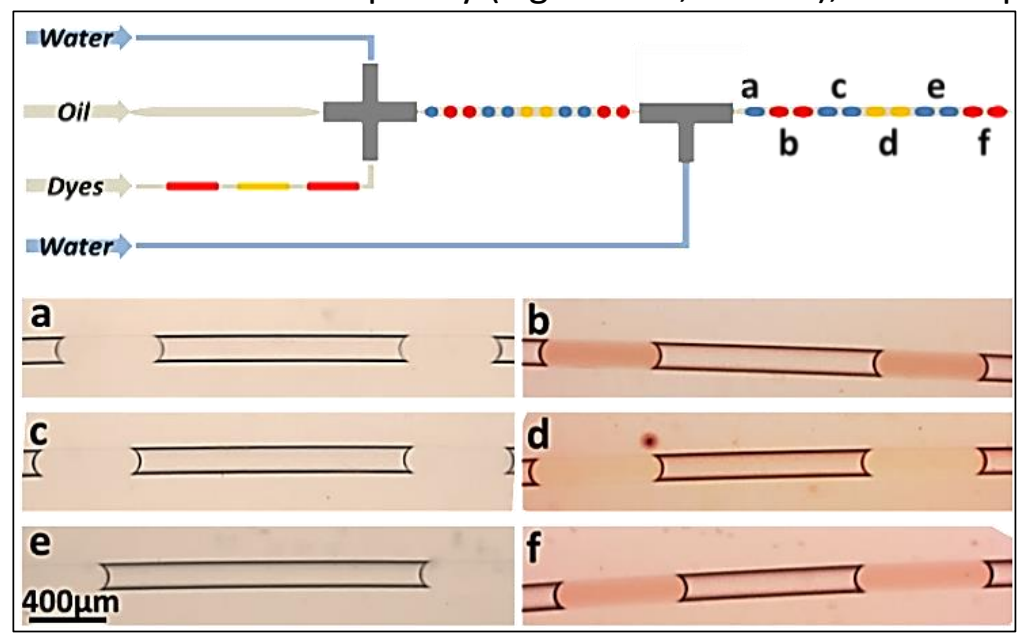

Figure 10: Successive addition of different solutions inside the droplets using the cross-junction in $150 \mu \mathrm{m}$ ID tubing. (a) to (f) show the droplets obtained from adding: (b-d-f) dyes and (a-c-e) oil. The flow-rates are: oil $140 \mu \mathrm{L} / \mathrm{h}$, cross-water $40 \mu \mathrm{L} / \mathrm{h}$, dyes $20 \mu \mathrm{L} / \mathrm{h}$ and tee-water $30 \mu \mathrm{L} / \mathrm{h}$.

However, ligands are usually only soluble in organic solvents whereas proteins are soluble in aqueous buffers. Thus, mixing ligand and protein solutions requires mixing two different phases during droplet generation. Note that the commonly used organic solvents are miscible with water (DMSO, ethanol). During droplet generation, we observed that droplets were at first regular (at the outlet of the cross-junction), but that they quickly coalesced in the tubing, especially since no surfactant was used to stabilize them. Indeed, the oil-water interfacial energy was higher than the oil-organic solvent interfacial energy (Table 1).

Thus, mixing aqueous solution and organic solvent first creates an interfacial energy gradient with oil, between the organic solvent-rich areas and the water-rich areas (before homogenization). This variation of the interfacial energy probably leads to a Marangoni flow. The result is a disturbance in the movement of generated droplets, causing their coalescence, as previously shown in the case of the addition of a surfactant. ${ }^{28}$ Moreover, once the droplets are homogeneous, their interfacial energy with the tubing wall is much lower than for pure-aqueous droplets. Hence droplets tend to wet the tubing wall, also promoting their coalescence. Therefore, it is impossible to add a pure organic solvent to water without disturbing the flow of generated droplets. 
Table 1: Interfacial energy of various solvents with FC-70 oil $\left(\mathrm{mJ} . \mathrm{m}^{-2}\right)$

\begin{tabular}{lc}
\hline Solvent & Interfacial energy \\
\hline Water & $48.40 \pm 0.51$ \\
DMSO & $18.14 \pm 0.06$ \\
DMF & $14.46 \pm 0.05$ \\
Methanol & $9.81 \pm 0.10$ \\
Ethanol & $7.83 \pm 0.02$ \\
\hline
\end{tabular}

To reduce the effects of interfacial energy changes, organic solvents were replaced by mixtures of organic solvent and water. Different proportions of water were tested with four organic solvents: DMSO, DMF, methanol and ethanol. For each proportion, the interfacial energy with FC-70 oil was measured, and droplet stability in the tubing was monitored (Figure 11). For all tested organic solvents, the addition of water improved the stability of the generated droplets. However, the proportion of water required for this stabilization varied from one organic solvent to another: for DMSO and DMF, only $10 \%$ water is required for droplet stabilization, as compared to $30 \%$ for methanol and $50 \%$ for ethanol. However, for all solvents, the value of the interfacial energy above which the droplets are stable in the tubing is in the range $15-20 \mathrm{~mJ} . \mathrm{m}^{-2}$ (Figure 11). This interfacial energy represents a limit below which the droplets are not stable in the tubing, and is very close to the critical surface energy of Teflon, $18 \mathrm{~mJ} . \mathrm{m}^{-2}{ }^{29}$ The critical surface energy of a solid surface gives the maximum interfacial energy of a liquid that wets the surface. Since the FEP surface of the tubing resembles that of Teflon, this confirms that the droplets become unstable and tend to coalesce when they wet the FEP tubing wall. Consequently, in this FEP microfluidic set-up, the dispersed phase (composing the droplets) must have an interfacial energy with the continuous phase higher than 15$20 \mathrm{~mJ} \cdot \mathrm{m}^{-2}$ to prevent droplets from coalescing.

Note that the mixtures of organic solvent and water still solubilize ligands, given that the concentrations required are low ( a few $\mathrm{mM})$. Moreover, proteins are not soluble in organic solvent. So as not to disturb their three-dimensional structure and compromise crystal quality, the final droplets must not contain more than $10 \%$ organic solvent. ${ }^{30}$ Thus, adding water to the ligand solutions also reduces the final amount of solvent in the crystallization droplets, decreasing the risk of protein denaturation.

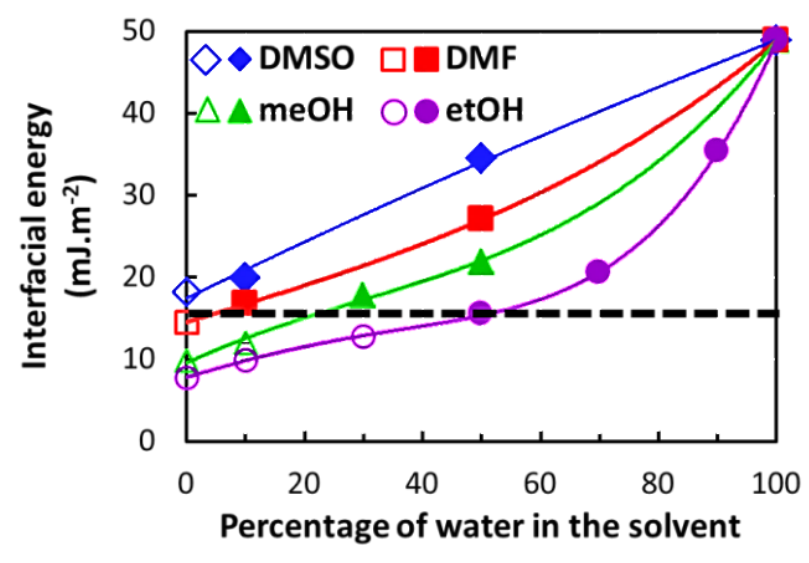

Figure 11: Interfacial energy of mixtures (organic solvent/water) with FC-70 oil, as a function of the percentage of water in the organic solvents: ethanol (circles), methanol (triangles), DMF (squares) and DMSO (diamonds). The empty symbols correspond to the conditions under which the droplets coalesce quickly in the tubing, and the full symbols to the conditions under which the generated droplets are stable in the tubing.

This set-up was applied to QR2 crystallization, adding first a 40\% DMSO solution, so that the final droplets contain 8\% DMSO. The crystals grown in these conditions (Figure 12) were similar to those obtained in pure aqueous solution (Figure 2), confirming that this DMSO concentration was low enough to preserve the protein structure and its crystallization. Then melatonin, a known QR2 
ligand ${ }^{20}$, was added to the droplets as a proof of concept for co-crystallization (Figure 13). We obtained crystals, which could be confirmed by further XRD analysis as QR2-melatonin co-crystals.

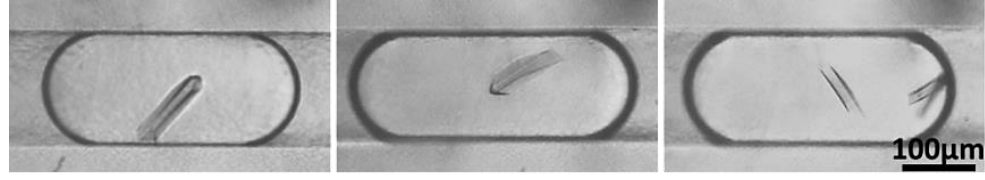

Figure 12: Pictures of 3 representative droplets for QR2 crystallization in presence of 8\% DMSO in $\sim 10 \mathrm{~nL}$ droplets. $6.7 \mathrm{mg}_{\mathrm{mL}}{ }^{-1},\left(\mathrm{NH}_{4}\right)_{2} \mathrm{SO}_{4} 1.3 \mathrm{M}, 150 \mathrm{mM} \mathrm{NaCl}, 20 \mathrm{mM}$ Tris- $\mathrm{HCl} \mathrm{pH} 8, \mathrm{DMSO} 8 \%, 20^{\circ} \mathrm{C}$.

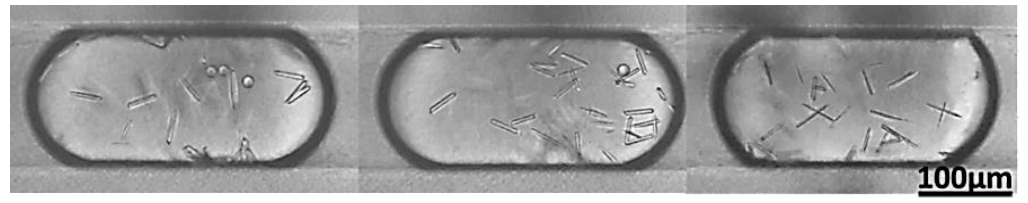

Figure 13: Pictures of 3 representative droplets for $Q R 2$ co-crystallization with melatonin in $\sim 10 \mathrm{~nL}$ droplets. QR2 6.7mg. $\mathrm{mL}^{-1},\left(\mathrm{NH}_{4}\right)_{2} \mathrm{SO}_{4} 1.5 \mathrm{M}, 150 \mathrm{mM} \mathrm{NaCl}, 20 \mathrm{mM}$ Tris- $\mathrm{HCl} \mathrm{pH}$ 8, $\mathrm{DMSO} 7 \%, 20^{\circ} \mathrm{C}$.

In conclusion, this method is suitable for preliminary screening to discriminate ligands favorable to protein crystallization from those which are not. After this selection, the cocrystallization can be optimized using the fine-gradient method presented here and previously. ${ }^{16}$

\section{Conclusion}

The droplet-based microfluidic platform described here is a flexible versatile tool for protein crystallization. Its three independent modules make it suitable for a wide range of applications: screening and optimization of crystallization conditions and screening of co-crystallization conditions. Easy to build and to use, the platform can be used to carry out a large number of crystallization trials quickly in droplets of only a few nanoliters, with small quantities of materials. The droplet composition is controlled by the respective flow-rates of the different solutions, and checked by on-line absorbance measurement. Commercially-available microfluidic junctions and tubing are combined to afford the number of inlets required and to create the desired geometry for droplet generation, without channel design and microfabrication stages. The absence of surfactant in droplets avoids any risk of its interaction with the nucleation process or with the protein threedimensional structure. Moreover, mixing aqueous and organic phases during droplet generation and circulation is rendered possible without using any surfactant.

Two examples of application to protein crystallization were presented here, using tubing as a "chemical library". First, screening and optimization of crystallization conditions of lysozyme, using only $0.2 \mathrm{mg}$ of protein for the entire study. Several crystallization agents placed in tubing form a "crystallization agent-based chemical library" and are successively added to droplets, making it possible to select the most efficient agent. Then crystallization conditions are optimized by varying the supersaturation inside the droplets via a fine concentration gradient. Thus, large single protein crystals are achieved. Second, the microfluidic geometry for a "ligand-based chemical library" is explored to co-crystallize the protein QR2 with ligand, for the purposes of structure-based drug design. Therefore, mixing the aqueous phase containing the protein and the crystallization agent with the organic phase containing the ligand is possible during droplet generation and circulation. The co-crystallization of QR2 protein dissolved in water with melatonin dissolved in DMSO validates the microfluidic geometry. The obtained protein-ligand co-crystals could be further analyzed by XRD in-situ (in glass tubing) or ex-situ (by extracting crystals from the Teflon tubing) ${ }^{19}$, or to solve the 3D structure, either to observe the ligand in the protein structure. 


\section{Acknowledgments}

We thank the Institut de Recherche Servier for financial support. We thank T. Bactivelane (CINaM), M. Lagaize (CINaM) and M. Audiffren (ANACRISMAT) for technical assistance. We thank Marjorie Sweetko for English revision.

\section{References}

(1) Blundell, T. L., Structure-based drug design. Nature 1996, 384, (6604 Suppl), 23-6.

(2) Maeki, M.; Yamaguchi, H.; Tokeshi, M.; Miyazaki, M., Microfluidic Approaches for Protein Crystal Structure Analysis. Analytical Sciences 2016, 32, (1), 3-9.

(3) Galkin, O.; Vekilov, P. G., Are Nucleation Kinetics of Protein Crystals Similar to Those of Liquid Droplets? Journal of the American Chemical Society 1999, 122, (1), 156-163.

(4) Hammadi, Z.; Grossier, R.; Ikni, A.; Candoni, N.; Morin, R.; Veesler, S., Localizing and inducing primary nucleation. Faraday Discussions 2015.

(5) Ferrer, J.-L.; Larive, N. A.; Bowler, M. W.; Nurizzo, D., Recent progress in robot-based systems for crystallography and their contribution to drug discovery. Expert Opinion on Drug Discovery 2013, $8,(7), 835-847$.

(6) Leng, J.; Salmon, J.-B., Microfluidic crystallization. Lab on a Chip 2009, 9, (1), 24-34.

(7) Candoni N.; Grossier R.; Hammadi Z.; Morin R.; Veesler S., Practical Physics Behind Growing Crystals of Biological Macromolecules Protein \& Peptide Letters 2012, 19, (7), 714-724.

(8) Hansen, C. L.; Skordalakes, E.; Berger, J. M.; Quake, S. R., A robust and scalable microfluidic metering method that allows protein crystal growth by free interface diffusion. Proceedings of the National Academy of Sciences 2002, 99, (26), 16531-16536.

(9) Perry, S. L.; Guha, S.; Pawate, A. S.; Bhaskarla, A.; Agarwal, V.; Nair, S. K.; Kenis, P. J. A., A microfluidic approach for protein structure determination at room temperature via on-chip anomalous diffraction. Lab on a Chip 2013, 13, (16), 3183-3187.

(10) Dhouib, K.; Malek, C. K.; Pfleging, W.; Gauthier-Manuel, B.; Duffait, R.; Thuillier, G.; Ferrigno, R.; Jacquamet, L.; Ohana, J.; Ferrer, J.-L.; Theobald-Dietrich, A.; Giege, R.; Lorber, B.; Sauter, C., Microfluidic chips for the crystallization of biomacromolecules by counter-diffusion and on-chip crystal X-ray analysis. Lab on a Chip 2009, 9, (10), 1412-1421.

(11) Otálora, F.; Gavira, J. A.; Ng, J. D.; García-Ruiz, J. M., Counterdiffusion methods applied to protein crystallization. Progress in Biophysics and Molecular Biology 2009, 101, (1-3), 26-37.

(12) Li, L.; Ismagilov, R. F., Protein crystallization using microfluidic technologies based on valves, droplets, and SlipChip. Annu Rev Biophys 2010, 39, 139-58.

(13) Zheng, B.; Gerdts, C. J.; Ismagilov, R. F., Using nanoliter plugs in microfluidics to facilitate and understand protein crystallization. Current Opinion in Structural Biology 2005, 15, (5), 548-555.

(14) Li, L.; Mustafi, D.; Fu, Q.; Tereshko, V.; Chen, D. L.; Tice, J. D.; Ismagilov, R. F., Nanoliter microfluidic hybrid method for simultaneous screening and optimization validated with crystallization of membrane proteins. Proc Natl Acad Sci U S A 2006, 103, (51), 19243-8.

(15) Gerdts, C. J.; Elliott, M.; Lovell, S.; Mixon, M. B.; Napuli, A. J.; Staker, B. L.; Nollert, P.; Stewart, L., The plug-based nanovolume Microcapillary Protein Crystallization System (MPCS). Acta Crystallogr D Biol Crystallogr 2008, 64, (Pt 11), 1116-22.

(16) Zhang, S.; Gerard, C. J. J.; Ikni, A.; Ferry, G.; Vuillard, L. M.; Boutin, J. A.; Ferte, N.; Grossier, R.; Candoni, N.; Veesler, S., Microfluidic platform for optimization of crystallization conditions. Journal of Crystal Growth 2017, 472, 18-28.

(17) Aune, K. C.; Tanford, C., Thermodynamics of the denaturation of lysozyme by guanidine hydrochloride. I. Dependence on pH at $25^{\circ}$. Biochemistry 1969, 8, (11), 4579-4585.

(18) Gasteiger, E.; Gattiker, A.; Hoogland, C.; Ivanyi, I.; Appel, R. D.; Bairoch, A., ExPASy: the proteomics server for in-depth protein knowledge and analysis. Nucleic Acids Research 2003, 31, (13), 3784-3788. 
(19) Gerard, C. J. J.; Ferry, G.; Vuillard, L. M.; Boutin, J. A.; Chavas, L. M. G.; Huet, T.; Ferte, N.; Grossier, R.; Candoni, N.; Veesler, S., Crystallization via tubing microfluidics permits both in situ and ex situ X-ray diffraction. Acta Crystallogr F Struct Biol Commun 2017, 73, (Pt 10), 574-578.

(20) Calamini, B.; Santarsiero, B. D.; Boutin, J. A.; Mesecar, A. D., Kinetic, thermodynamic and Xray structural insights into the interaction of melatonin and analogues with quinone reductase 2. Biochem J 2008, 413, (1), 81-91.

(21) Arashiro, E. Y.; Demarquette, N. R., Use of the pendant drop method to measure interfacial tension between molten polymers. Materials Research 1999, 2, 23-32.

(22) Ildefonso, M.; Candoni, N.; Veesler, S., A Cheap, Easy Microfluidic Crystallization Device Ensuring Universal Solvent Compatibility. Organic Process Research \& Development 2012, 16, (4), 556-560.

(23) Seemann, R.; Brinkmann, M.; Pfohl, T.; Herminghaus, S., Droplet based microfluidics. Rep Prog Phys 2012, 75, (1), 016601.

(24) Zhang, S.; Guivier-Curien, C.; Veesler, S.; Candoni, N., Prediction of sizes and frequencies of nanoliter-sized droplets in cylindrical T-junction microfluidics. Chemical Engineering Science 2015, $138,128-139$.

(25) Trivedi, V.; Doshi, A.; Kurup, G. K.; Ereifej, E.; Vandevord, P. J.; Basu, A. S., A modular approach for the generation, storage, mixing, and detection of droplet libraries for high throughput screening. Lab Chip 2010, 10, (18), 2433-42.

(26) Tanaka, S. Y., M. ; Ito, K. ; Hayakawa R., Relation between the phase transition and the crystallization in protein solutions. Physical Review 1997, E 56, (n¹), 67-69.

(27) Ildefonso, M.; Revalor, E.; Punniam, P.; Salmon, J. B.; Candoni, N.; Veesler, S., Nucleation and polymorphism explored via an easy-to-use microfluidic tool. Journal of Crystal Growth 2012, 342, (1), 9-12.

(28) Baroud, C. N.; Gallaire, F.; Dangla, R., Dynamics of microfluidic droplets. Lab on a Chip 2010, 10, (16), 2032-2045.

(29) Sharma, P. K.; Hanumantha Rao, K., Analysis of different approaches for evaluation of surface energy of microbial cells by contact angle goniometry. Advances in Colloid and Interface Science 2002, 98, (3), 341-463.

(30) Mande, S. C.; Sobhia, M. E., Structural characterization of protein-denaturant interactions: crystal structures of hen egg-white lysozyme in complex with DMSO and guanidinium chloride. Protein Engineering, Design and Selection 2000, 13, (2), 133-141. 